\title{
Three-dimensional physical simulation and optimization of water injection of a multi-well fractured-vuggy unit
}

\author{
Ji-Rui Hou ${ }^{1,2,3} \cdot$ Ze-Yu Zheng ${ }^{1,2,3} \cdot$ Zhao-Jie Song ${ }^{1,2,3} \cdot$ Min Luo ${ }^{1,2,3}$ • \\ Hai-Bo Li ${ }^{1,2,3} \cdot$ Li Zhang ${ }^{1,2,3} \cdot$ Deng-Yu Yuan ${ }^{1,2,3}$
}

Received: 3 December 2014/ Published online: 16 March 2016

(C) The Author(s) 2016. This article is published with open access at Springerlink.com

\begin{abstract}
With complex fractured-vuggy heterogeneous structures, water has to be injected to facilitate oil production. However, the effect of different water injection modes on oil recovery varies. The limitation of existing numerical simulation methods in representing fracturedvuggy carbonate reservoirs makes numerical simulation difficult to characterize the fluid flow in these reservoirs. In this paper, based on a geological example unit in the Tahe Oilfield, a three-dimensional physical model was designed and constructed to simulate fluid flow in a fractured-vuggy reservoir according to similarity criteria. The model was validated by simulating a bottom water drive reservoir, and then subsequent water injection modes were optimized. These were continuous (constant rate), intermittent, and pulsed injection of water. Experimental results reveal that due to the unbalanced formation pressure caused by pulsed water injection, the swept volume was expanded and consequently the highest oil recovery increment was achieved. Similar to continuous water injection, intermittent injection was influenced by factors including the connectivity of the fractured-vuggy reservoir, well depth, and the injection-production relationship, which led to a relative low oil recovery. This study may provide a
\end{abstract}

Ze-Yu Zheng

zhengzeyu890808@outlook.com

1 Research Institute of Enhanced Oil Recovery, China University of Petroleum, Beijing 102249, China

2 Key Laboratory of Marine Facies, Sinopec, Beijing 102249, China

3 Key Laboratory of Petroleum Engineering, Ministry of Education, Beijing 102249, China

Edited by Yan-Hua Sun constructive guide to field production and for the development of the commercial numerical models specialized for fractured-vuggy carbonate reservoirs.

Keywords Multi-well fractured-vuggy unit . Three-dimensional physical model - Similarity criteria . Bottom water drive . Optimization of water injection mode

\section{Introduction}

Carbonate reservoirs are the important sources of hydrocarbons, accounting for half of world's oil and gas reserves (Li and Chen 2013; Yousef et al. 2014). The Tahe Oilfield is the largest oilfield found in the Paleozoic marine carbonates in China ( $\mathrm{Li}$ et al. 2014a). The successful exploitation of this oilfield can significantly reduce the crisis of the hydrocarbon shortage in China.

The Tahe Oilfield is located in the middle of the South Tarim Uplift in the Tarim Basin, China, with an area of $2400 \mathrm{~km}^{2}$ (Li et al. 2014b). The Ordovician reservoir in the Tahe Oilfield is an example of fractured-vuggy carbonate reservoirs ( $\mathrm{Li} \mathrm{2013).} \mathrm{The} \mathrm{reservoir} \mathrm{space} \mathrm{is} \mathrm{complicated}$ because of the co-existence of vugs, fractures, and large caves in these reservoirs (Xu et al. 2012). Large caves serve as the main storage space, while fractures act as the primary flow paths with only a little oil accumulated in them (Lv et al. 2011; Zhang and Wang 2004). On the other hand, the carbonate matrix exhibits ultra-low permeability and almost no storage ability. Therefore, a fractured-vuggy unit is considered as the basic production unit during the exploitation of these carbonate reservoirs (Yi et al. 2011; Rong et al. 2013). This type of reservoir is characterized by serious heterogeneity, random distribution, and complex co-location of fractures and vugs, and various filling types 
and filling percentages of storage space. Therefore, fractured-vuggy carbonate reservoirs are very complex with multiple oil-water systems and the existence of bottom water, which makes hydrocarbon production difficult (Popov et al. 2009; Lucia et al. 2003).

And so far, in most of the numerical simulations of fractured-vuggy carbonate reservoirs, this type of reservoir is taken as equivalent to sandstone reservoirs, e.g., CMG, Eclipse (Presho et al. 2011; Wu et al. 2011; Guo et al. 2012). A commercial numerical simulator specialized for fractured-vuggy carbonate reservoirs has not yet been developed. Consequently, fundamental experimental research is required to provide a theoretical foundation for numerical simulations.
Previous research has been conducted on fracturedvuggy reservoirs through physical simulations (Cruz et al. 2001; Zheng et al. 2010; Zhang et al. 2011; Jia et al. 2013; $\mathrm{Xu}$ et al. 2013). Cruz et al. (2001) performed water-displacing oil experiments using a two-dimensional vuggy fractured porous cell, took photographs of the water front, measured the flow area corresponding to oil and water, and finally developed a theoretical model based on the experimental results. Zheng et al. (2010) designed and constructed a cylindrical core model, according to actual conditions of a fractured-vuggy carbonate reservoir. Water-displacing oil experiments were conducted and it is found that oil recovery, water cut, and water breakthrough were significantly impacted by fractured-vuggy structures. Zhang et al. (2011)

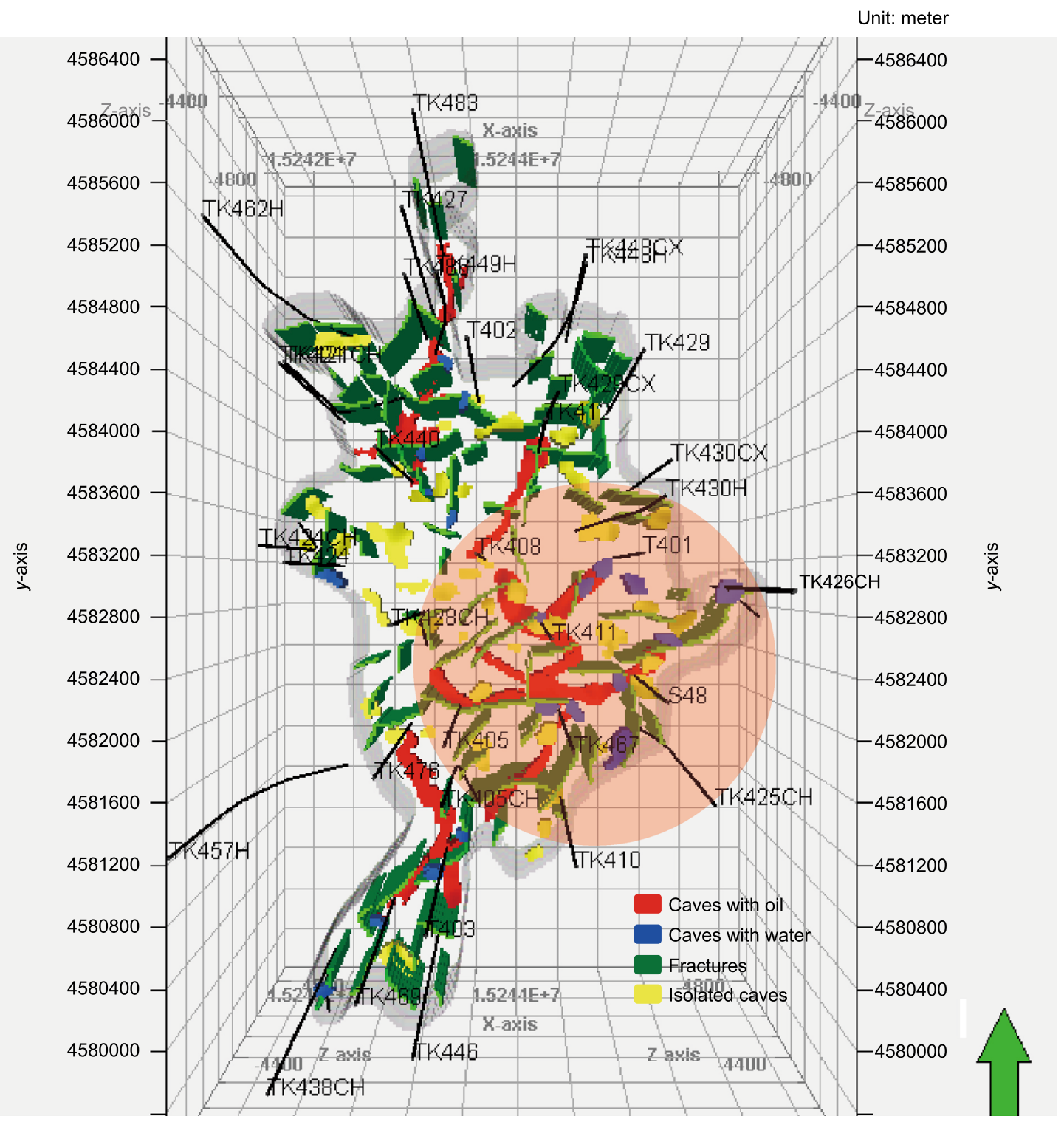

Fig. 1 Geological conditions of the example reservoir 
built a single-phase fluid flow pattern in fractured-vuggy media with different vug densities, and concluded that with an increase in vug density, the pressure gradient at the same velocity declined and the critical velocity increased. However, due to the limitations of dimensionality, similarity design, and other factors, three-dimensional fluid flow in porous media is difficult to simulate reliably in these models. In this paper, a three-dimensional physical model is designed and built based on a geological example unit in the Tahe Oilfield and similarity criteria. Bottom water drive is conducted to validate the $3 \mathrm{D}$ physical model according to well history and then the optimization of water injection
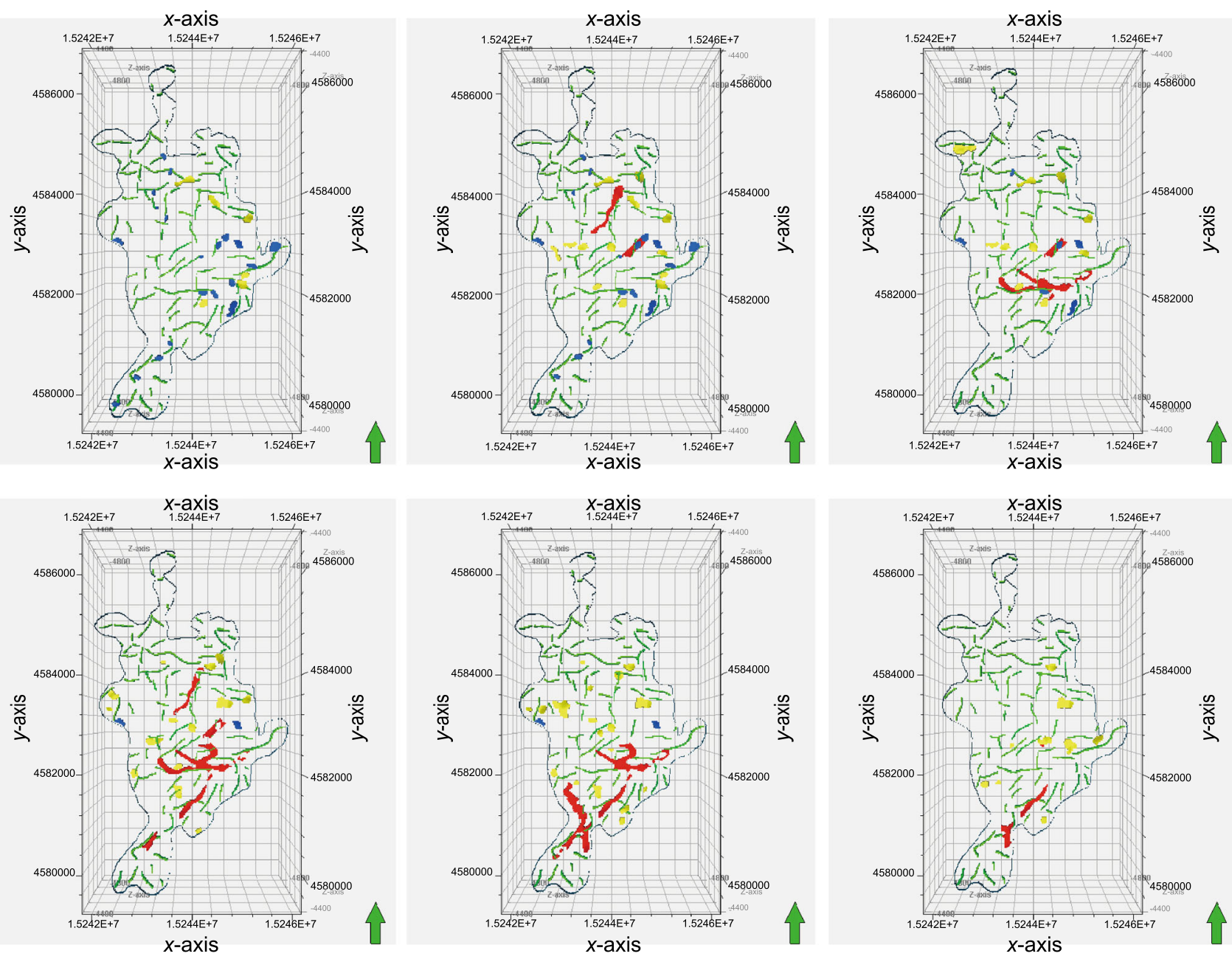

Fig. 2 Longitudinal sections of the reservoir

Table 1 Production histories of 5 wells with bottom water drive in the S48 unit

\begin{tabular}{llllll}
\hline Well & Production date & Production duration, $y$ & Crude output, $10^{4} \mathrm{~m}^{3}$ & Liquid output, $10^{4} \mathrm{~m}^{3}$ & Annual liquid output, $10^{4} \mathrm{~m}^{3} / \mathrm{y}$ \\
\hline S48 & 1997 & 12 & 80.04 & 94.02 & 7.83 \\
T401 & 1998 & 11 & 50.17 & 63.24 & 5.75 \\
TK411 & 1999 & 10 & 12.87 & 18.61 & 1.86 \\
Tk426CH & 2000 & 9 & 2.650 & 10.73 & 1.19 \\
TK467 & 2002 & 7 & 9.714 & 14.21 & 2.03 \\
\hline
\end{tabular}


Table 2 Annual data of the S48 unit with bottom water drive

\begin{tabular}{lll}
\hline Year & $\begin{array}{l}\text { Annual liquid } \\
\text { output, } 10^{4} \mathrm{~m}^{3}\end{array}$ & $\begin{array}{l}\text { Daily liquid } \\
\text { output, } \mathrm{m}^{3} / \mathrm{d}\end{array}$ \\
\hline $1997^{*}$ & 2.889 & 481.4 \\
1998 & 17.36 & 475.7 \\
1999 & 31.13 & 852.9 \\
2000 & 41.50 & 1137 \\
2001 & 29.33 & 803.5 \\
2002 & 23.40 & 373.2 \\
2003 & 12.20 & 334.2 \\
2004 & 9.340 & 255.9 \\
2005 & 9.328 & 255.6 \\
2006 & 10.04 & 275.0 \\
2007 & 11.91 & 326.4 \\
2008 & 14.78 & 404.9 \\
\hline
\end{tabular}

* The wells only produced for two months in 1997 modes is performed by means of continuous, intermittent, and pulsed injection of water.

The experimental results may provide an insight into the later production with water injection and numerical simulations of fractured-vuggy carbonate reservoirs.

\section{Geological example and well history}

\subsection{Example reservoir}

Five wells, S48, T401, TK411, TK426CH, and TK467, in the S48 unit in the Tahe Oilfield were chosen as examples to design a 3D physical model, as shown in Fig. 1. The red part in Fig. 1 indicates the area of influence of the chosen well groups. The longitudinal sections of the reservoir are presented in Fig. 2.
Table 3 Physical parameters and dimensions related to oil and water two-phase flow in a multi-well fractured-vuggy unit

\begin{tabular}{|c|c|c|c|c|}
\hline Category & Number & Physical parameter & Symbol & Dimension \\
\hline \multirow[t]{3}{*}{ Basic physical parameter } & 1 & Quality & $m$ & M \\
\hline & 2 & Time & $t$ & $\mathrm{~T}$ \\
\hline & 3 & Length & $l$ & $\mathrm{~L}$ \\
\hline \multirow[t]{18}{*}{ Dimensional parameter } & 4 & Oil flow rate & $u_{\mathrm{o}}$ & $\mathrm{LT}^{-1}$ \\
\hline & 5 & Water flow rate & $u_{\mathrm{w}}$ & $\mathrm{LT}^{-1}$ \\
\hline & 6 & Oil density & $\rho_{\mathrm{o}}$ & $\mathrm{ML}^{-3}$ \\
\hline & 7 & Water density & $\rho_{\mathrm{w}}$ & $\mathrm{ML}^{-3}$ \\
\hline & 8 & Oil viscosity & $\mu_{\mathrm{o}}$ & $\mathrm{ML}^{-1} \mathrm{~T}^{-1}$ \\
\hline & 9 & Water viscosity & $\mu_{\mathrm{w}}$ & $\mathrm{ML}^{-1} \mathrm{~T}^{-1}$ \\
\hline & 10 & Volume flow rate of oil & $Q_{\mathrm{o}}$ & $\mathrm{L}^{3} \mathrm{~T}^{-1}$ \\
\hline & 11 & Volume flow rate of water & $Q_{\mathrm{w}}$ & $\mathrm{L}^{3} \mathrm{~T}^{-1}$ \\
\hline & 12 & Injection pressure & $P$ & $\mathrm{ML}^{-1} \mathrm{~T}^{-2}$ \\
\hline & 13 & Acceleration of gravity & $g$ & $\mathrm{LT}^{-2}$ \\
\hline & 14 & Fracture permeability & $K_{\mathrm{f}}$ & $\mathrm{L}^{2}$ \\
\hline & 15 & Cave height & $H$ & $\mathrm{~L}$ \\
\hline & 16 & Fracture aperture & $B$ & $\mathrm{~L}$ \\
\hline & 17 & Cave diameter & $d$ & $\mathrm{~L}$ \\
\hline & 18 & Fracture density & $n_{\mathrm{f}}$ & $\mathrm{L}^{-1}$ \\
\hline & 19 & Cave density & $n_{\mathrm{v}}$ & $\mathrm{L}^{-2}$ \\
\hline & 20 & Fluid compressibility & $C_{\mathrm{L}}$ & $\mathrm{LT}^{2} \mathrm{M}^{-1}$ \\
\hline & 21 & Total compressibility & $C_{\mathrm{t}}$ & $\mathrm{LT}^{2} \mathrm{M}^{-1}$ \\
\hline \multirow[t]{8}{*}{ Dimensionless parameter } & 22 & Fracture porosity & $\Phi_{\mathrm{f}}$ & \\
\hline & 23 & Cavernous porosity & $\Phi_{\mathrm{v}}$ & \\
\hline & 24 & Oil relative permeability & $K_{\text {ro }}$ & \\
\hline & 25 & Water relative permeability & $K_{\mathrm{rw}}$ & \\
\hline & 26 & Oil saturation & $S_{\mathrm{o}}$ & \\
\hline & 27 & Water saturation & $S_{\mathrm{w}}$ & \\
\hline & 28 & Pseudo coordination number & $\xi$ & \\
\hline & 29 & Filling percentage & $\eta$ & \\
\hline
\end{tabular}




\subsection{Well history}

A 3D physical model was constructed based on the example of the geology of the S48 unit. Bottom water drive was employed in the S48 unit in the early stage of production. The physical model was required to be similar to actual reservoir conditions so that experimental results are as reliable as possible. Hence, it is imperative to understand and analyze the practical production situations during bottom water drive. Tables 1 and 2 depict well history information of the S48 unit. According to well history and other information reported earlier (Zhu et al. 2009; Hu et al. 2013), an oil recovery of $20 \%-23 \%$ was obtained at the end of bottom water drive in this unit.

\section{Physical model design and fabrication}

\subsection{Similarity design}

According to previous studies of physical simulation (Elkaddifi et al. 2008; Zhang et al. 2008; Bünger and Herwig 2009; Zuta and Fjelde 2011; Wang et al. 2014), some similarity criteria, such as geometric similarity, kinematic similarity, dynamic similarity, and characteristic parameter similarity, were adopted to insure the similarity between the physical model and the geological example.
However, it was impossible to achieve similarity of all parameters. Thus, a dimensional analysis method was introduced to simplify the similarity criterions.

The characteristics of oil and water two-phase flow in a multi-well fractured-vuggy unit should be taken into account and relevant physical parameters were considered as illustrated in Table 3.

According to Buckingham's pi-theorem (Haftkhani and Arabi 2013), $\rho, u$, and $l$ were chosen as basic parameters, and the physical parameters with the same dimensions were classified as a group. The similarity criterion group is obtained as shown in Table 4.

For a specific flow model, the flow field in the physical model is generally similar to that in the actual reservoir when some main similarity criteria are achieved (Kang and Tang. 2014; Nam et al. 2014). The ratio of the cave diameter to the diameter of the area of influence was chosen as a criterion for geometric similarity. Since the bottom water drive is required to be simulated, the liquid production rate and production duration should be similar to actual situations, so $\pi 6$ and $\pi 7$ in Table 4 were chosen as kinematic similarity criteria. The Reynolds number should be considered when dynamic similarity is discussed. Meanwhile, the ratio of pressure to gravity that influences the fluid distribution in displacement processes needed to be considered. In addition, the physical model should comply with the similarity theorem on some characteristic parameters, such as pseudo coordination number and
Table 4 Similarity criterion group of the multi-well fractured-vuggy unit

\begin{tabular}{llll}
\hline Geometric similarity & Kinematic similarity & Dynamic similarity & Characteristic parameter similarity \\
\hline$\pi 1=d / l$ & $\pi 6=Q /\left(u l^{2}\right)$ & $\pi 8=\mu /(\rho u l)$ & $\pi 11=\xi$ \\
$\pi 2=B / l$ & $\pi 7=t u / l$ & $\pi 9=P /\left(\rho u^{2}\right)$ & $\pi 12=\eta$ \\
$\pi 3=K_{\mathrm{f}} / l^{2}$ & - & $\pi 10=g l / u^{2}$ & $\pi 13=n_{\mathrm{f}} l$ \\
$\pi 4=\Phi_{\mathrm{f}}$ & - & - & $\pi 14=n_{\mathrm{v}} l^{2}$ \\
$\pi 5=\Phi_{\mathrm{v}}$ & - & - & - \\
\hline
\end{tabular}

Table 5 Comparison of parameters of the example reservoir and the physical model

\begin{tabular}{llll}
\hline Parameter & Example reservoir & Physical model & Similarity coefficient \\
\hline Cave diameter & $5-25 \mathrm{~m}$ & $3-12 \mathrm{~cm}$ & $166.7-200.0$ \\
Differential pressure & $2-14 \mathrm{MPa}$ & $10-60 \mathrm{kPa}$ & $200.0-233.3$ \\
Oil viscosity & $19.7-28.5 \mathrm{mPa} \mathrm{s}$ & $65 \mathrm{mPa} \mathrm{s}$ & $0.3038-0.4377$ \\
Oil density & $0.92 \mathrm{~g} / \mathrm{cm}^{3}$ & $0.8 \mathrm{~g} / \mathrm{cm}^{3}$ & 1.150 \\
Acceleration of gravity & $9.8 \mathrm{~m} / \mathrm{s}^{2}$ & $9.8 \mathrm{~m} / \mathrm{s}^{2}$ & 1.000 \\
Fracture density & $3-50 / \mathrm{m}$ & $50 / \mathrm{m}$ & $0.05880-1.000$ \\
Fracture aperture & $0.5-5 \mathrm{~mm}$ & $2-4.5 \mathrm{~mm}$ & $0.2500-1.110$ \\
Fluid flow velocity & $30-135 \mathrm{~m} / \mathrm{d}$ & $0.022-0.152 \mathrm{~m} / \mathrm{s}$ & $0.001585-0.001903$ \\
Liquid production rate & $255.6-1137 \mathrm{~m}^{3} / \mathrm{d}$ & $4-10 \mathrm{~mL} / \mathrm{min}$ & $44.37-78.97$ \\
Production duration & 1 year & $5 \mathrm{~min}$ & $1.051 \times 10^{5}$ \\
Filling percentage & $0 \%-100 \%$ & $0 \%-100 \%$ & 1 \\
Coordination number & $1-5$ & $1-5$ & 1 \\
\hline
\end{tabular}


filling percentage. Since it is difficult for a physical model to satisfy multiple similarity criteria simultaneously, the Reynolds number should always be given priority.

The index of the similarity criteria was calculated according to similarity coefficients. A similarity coefficient is the ratio of field parameters to model parameters. If a certain index of the similarity criterion is 1 , this model parameter is fully compliant with the field parameter. Based on the discussion mentioned above, the similarity coefficients and similarity indices of the physical model are obtained as shown in Tables 5 and 6.

\subsection{Model fabrication}

Longitudinal sections of the example reservoir were divided into six layers, as shown in Fig. 3. Caves and fractures were carved in each core based on the example reservoir. After that, these six cores were bonded together in a given

Table 6 Similarity indices of the physical model

\begin{tabular}{|c|c|c|c|c|}
\hline Similarity condition & $\begin{array}{l}\text { Similarity } \\
\text { criterion }\end{array}$ & Physical meaning & Source & $\begin{array}{l}\text { Similarity } \\
\text { index }\end{array}$ \\
\hline Geometric similarity & $d / l$ & $\begin{array}{l}\text { The ratio of the cave diameter to the diameter of the area of } \\
\text { influence }\end{array}$ & $\pi 1$ & 1 \\
\hline \multirow[t]{2}{*}{ Kinematic similarity } & $\rho u l / \mu$ & Reynolds number (the ratio of inertia force to viscous force) & $1 / \pi 8$ & 1 \\
\hline & $P /(\rho g l)$ & The ratio of the injection pressure to gravity & $\pi 9 /$ & $1.01-1.04$ \\
\hline \multirow[t]{2}{*}{ Dynamic similarity } & $Q /\left(u l^{2}\right)$ & The ratio of the liquid production rate to the injection rate & $\pi 6$ & $1.01-1.04$ \\
\hline & tull & The ratio of the production duration to the injection duration & $\pi 7$ & 1 \\
\hline \multirow{2}{*}{$\begin{array}{l}\text { Characteristic parameter } \\
\text { similarity }\end{array}$} & $\xi$ & Pseudo coordination number & $\pi 11$ & 1 \\
\hline & $\eta$ & Filling percentage & $\pi 12$ & 1 \\
\hline
\end{tabular}
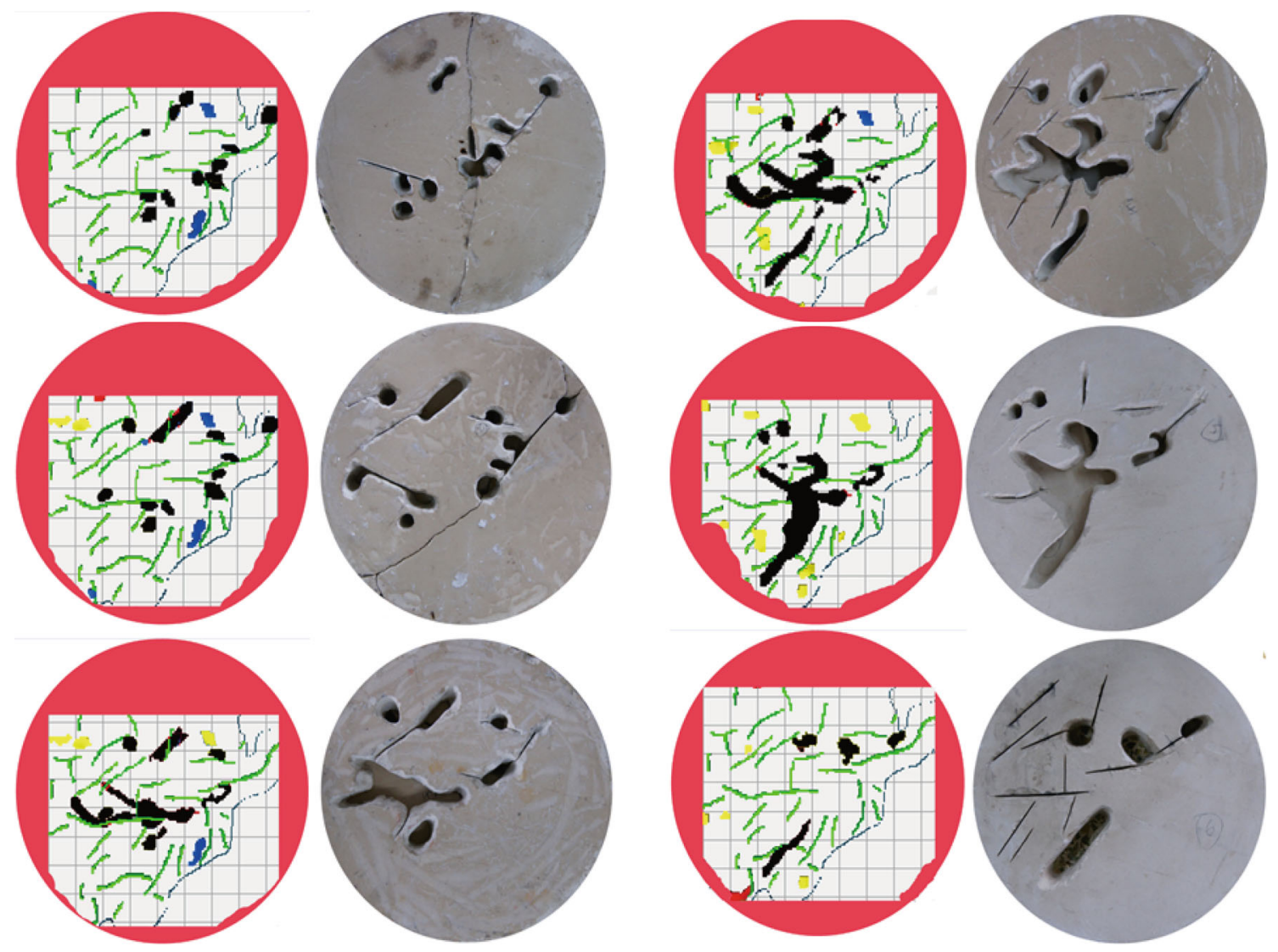

Fig. 3 Comparison of the fractured-vuggy structures between the physical model and the real core for each layer 
order. The flow paths of the bottom water and well locations were designed, and a three-dimensional model was fabricated. Finally, the model was put into a cylindrical mold and it was encapsulated and fixated with epoxy resin, as presented in Fig. 4. More details of the physical model were described elsewhere (Hou et al. 2014).

\subsection{Fracture and cave structures and well locations}

A fractured-vuggy unit with a complex structure was formed in a 3D space, as shown in Fig. 5. In order to make the model similar to the actual formation, caves and fractures were filled with gravel in a certain order of completely filled, half-filled, and unfilled from bottom to top.

Five wells were drilled in the model according to the designed depths and locations. These wells were drilled in different reservoir bodies, i.e., cave and fracture. Wells were divided into two types: one is cave-well which is marked by " $\mathrm{D}$ " and the other is fracture-well marked by "L." Figure 6 illustrates the well locations and Table 7 shows the well parameters.

\section{Experimental}

\subsection{Experimental apparatus and materials}

The experimental apparatus (Fig. 7) included a 3D physical model, three intermediate containers, two water injection pumps with a pressure range of $0-30 \mathrm{MPa}$ and a flow rate range of $0.01-10.00 \mathrm{~mL} / \mathrm{min}$, several pressure transducers, some six-port valves, etc.

The simulated oil used was a mixture of kerosene and dehydrated crude, with a viscosity of $65 \mathrm{mPa} \mathrm{s}$ at $25^{\circ} \mathrm{C}$.
The simulated formation water used had a salinity of $2 \times 10^{5} \mathrm{mg} / \mathrm{L}$.

\subsection{Experimental procedures}

The experimental procedures are as follows:

(1) The physical model was evacuated and then saturated with the simulated formation water at $10 \mathrm{~mL} /$ min from pipelines 6 in Fig. 7. The total volume of water injected into the model was measured to calculate the pore volume (PV) of fractures and caves in the physical model.

(2) The model was flooded with the simulated oil at $10 \mathrm{~mL} / \mathrm{min}$ from pipelines 13 from the top of the model and the water was drained from pipelines 6 . This was continued until no more water was drained.

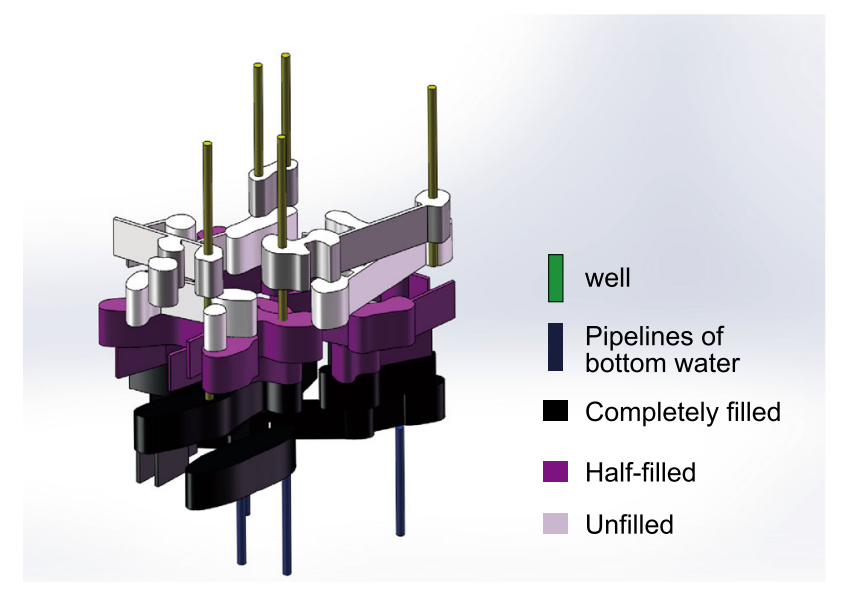

Fig. 5 Fractured-vuggy structure inside the three-dimensional physical model

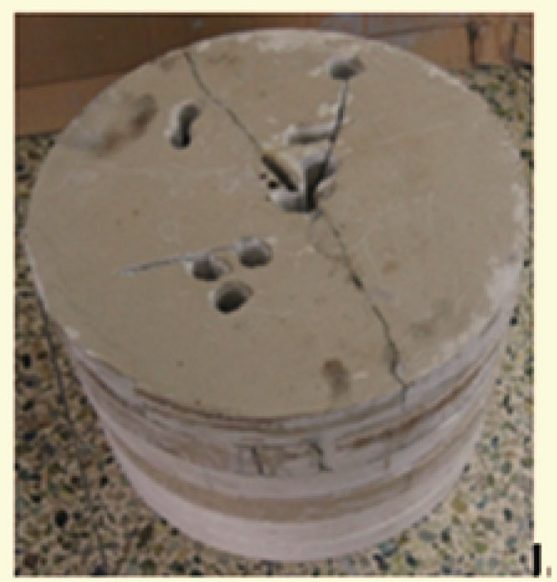

Fig. 4 The real core after combination 
The total volume of water displaced from the model was measured, and the initial oil saturation and the water saturation of the model were then calculated.

(3) As shown in Fig. 7a, the simulated formation water was continuously introduced into the bottom of the model; the water injection rate was varied to simulate the stage of depletion of a bottom water drive reservoir. The initial water injection rate was set at $10 \mathrm{~mL} / \mathrm{min}$ and then decreased to $6 \mathrm{~mL} / \mathrm{min}$ after $15 \mathrm{~min}$, and to $4 \mathrm{~mL} / \mathrm{min}$ after another $5 \mathrm{~min}$. The injection rate was kept at $4 \mathrm{~mL} / \mathrm{min}$ until a $98 \%$ water cut was reached in one of these five production wells. The oil and water production rate was monitored to calculate oil recovery and periodic water cut. Five wells were put into production in the order D1, D2, L2, L3, and L1, as depicted in Table 8.

(4) During the bottom water drive, the water cut of Well L1 reached $98 \%$ first. This well was then switched to be an injection well. After the bottom water drive, the experimental apparatus was set up as shown in Fig. 7b. Water was subsequently introduced into the model through Well L1; water injection rates at

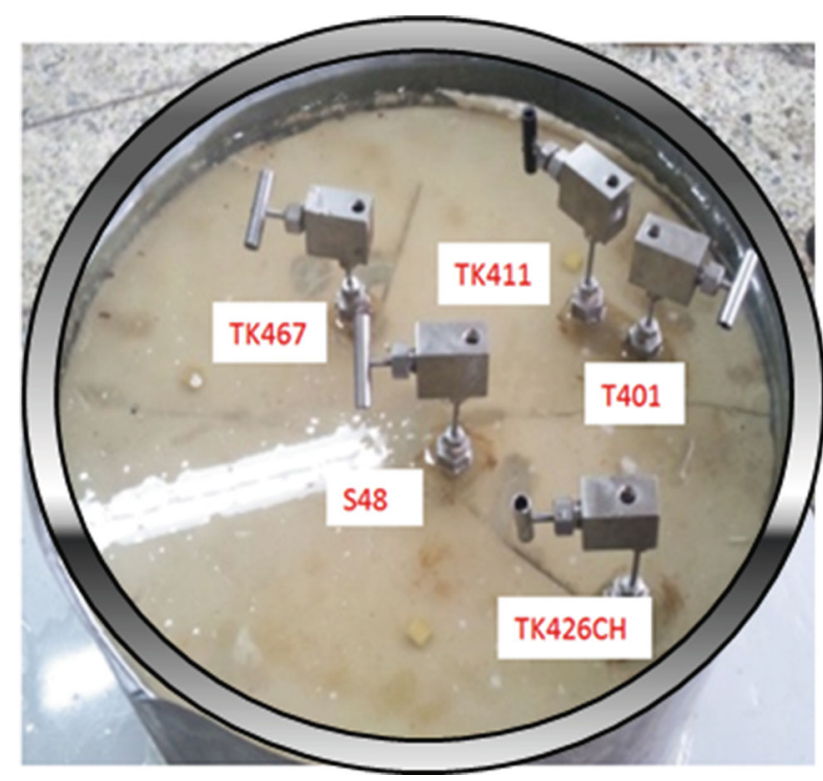

Fig. 6 Well locations in the three-dimensional physical model different waterflood projects are listed in Table 9. Each production well was shut in once its water cut reached $98 \%$. The experiment was stopped when the four production wells were all shut in. The oil and water production rates were monitored to calculate the oil recovery and periodic water cut.

\section{Experimental results and discussion}

\subsection{Performance of the bottom water drive model}

The production performance of the bottom water drive model constructed in this study is shown in Fig. 8. The oil recoveries of five production wells increased slowly at this stage, i.e., the oil production rate declined, and the water cut of fluids produced from Well L1 increased as the bottom water energy was depleted.

Water breakthrough occurred immediately in Well L1 and its water cut rose rapidly after this well was put into production. This is because Well L1 was the deepest well (Table 7). Experimental results are consistent with actual production situation. The experiment was stopped when the water cut of fluids produced from Well L1 reached $98 \%$. The total oil recovery was about $22.1 \%$, which is in agreement with the actual oil recovery in the S48 unit. Thus, experimental results verified that the 3D physical model had similarity to the example reservoir (S48 unit).

\subsection{Optimization of water injection schemes}

Due to the viscosity difference between water and oil in the water/oil interface, the flow rate of water is higher than that of oil under the same differential pressure. When the differential pressure is high enough, water can probably flow vertically upward. Therefore, a conical water/oil interface was formed, which is known as bottom water coning (Xiao et al. 2010).

By injecting water into the reservoir through a drowned well to supply energy, bottom water coning could be mitigated and the intrusive water phase could be suppressed toward the opposite direction ( $\mathrm{Lu}$ et al. 2009). However, different water injection modes exert different effects on
Table 7 Well parameters of the models

\begin{tabular}{lllll}
\hline Number & Well & Well depth, cm & Well type & Filling percentage \\
\hline D1 & S48 & 14.8 & Cave-well & Half-filled \\
D2 & T401 & 12.2 & Cave-well & Half-filled \\
L1 & TK467 & 18.0 & Fracture-well & Completely filled \\
L2 & TK411 & 17.8 & Fracture-well & Completely filled \\
L3 & TK426CH & 9.2 & Fracture-well & Unfilled \\
\hline
\end{tabular}




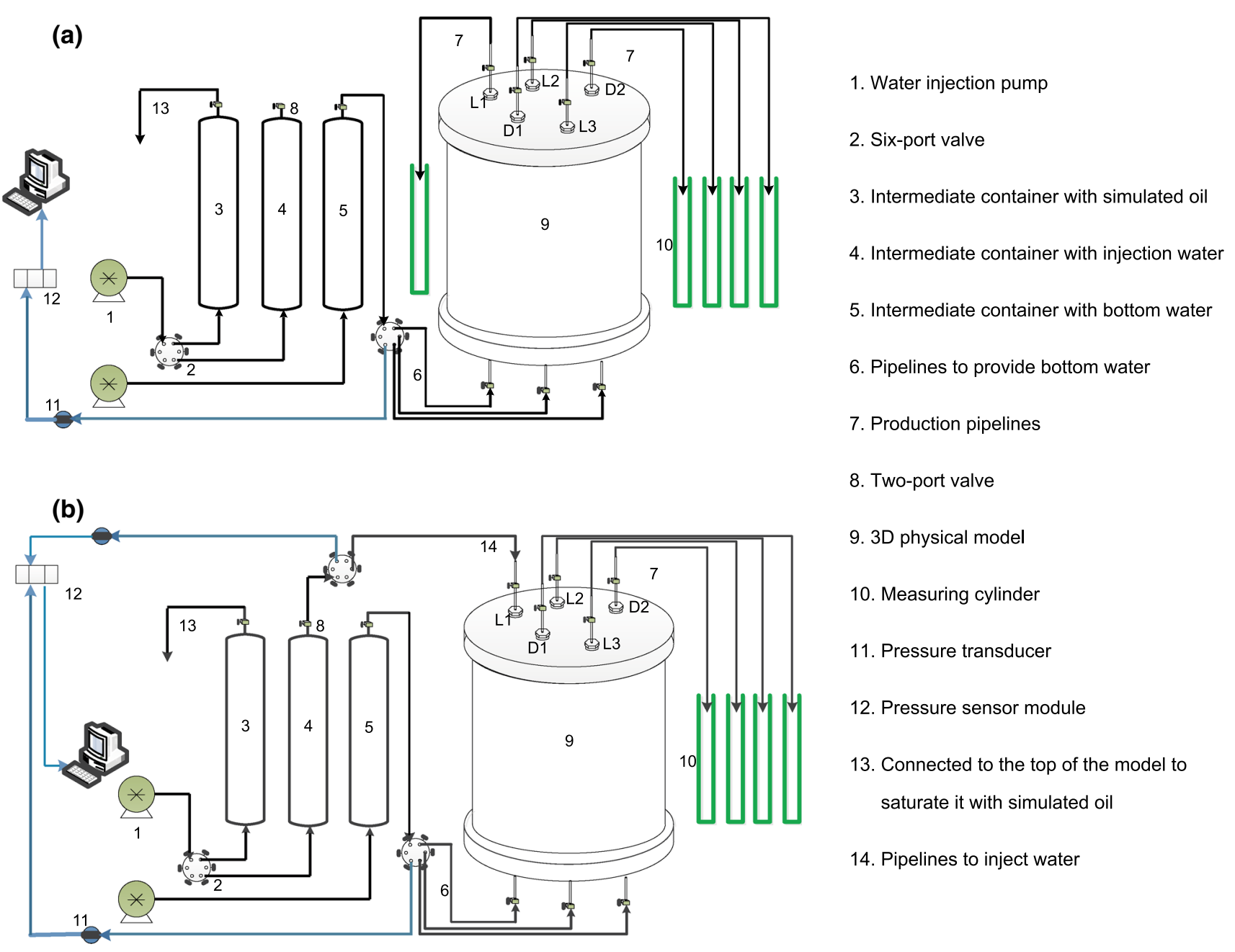

Fig. 7 Schematic diagram of experimental setups for the bottom water drive (a) and the water injection mode optimization (b)

Table 8 Well startup order in the bottom water drive model

\begin{tabular}{ll}
\hline Timing, min & Well startup order \\
\hline 0 & D1 \\
5 & D2 \\
10 & L2 \\
15 & L3 \\
25 & L1 \\
\hline
\end{tabular}

mitigating water coning. Therefore, the objective of the following work is to optimize water injection modes, including continuous injection (constant rate), intermittent injection, and pulsed injection of water.

\subsubsection{Overall effect of subsequent water injection}

Figures 9 and 10 show the dynamic curves of oil recovery and differential pressure for three water injection schemes, respectively.
No matter which water injection scheme was performed, the oil recovery increased substantially at the beginning and then continued to rise smoothly until the oil recovery became relatively stable as no more oil was being produced. The highest oil recovery of $47.0 \%$ was obtained after pulsed injection of water. Similar oil recoveries, $44.7 \%$ and $44.3 \%$, respectively, were obtained after continuous and intermittent injection of water.

The differential pressure fluctuated significantly during intermittent and pulsed injection of water (Fig. 10). The amplitude of pressure fluctuations was relatively large when water was intermittently injected into Well L1 every $25 \mathrm{~min}$, while the frequency of pressure fluctuations was relatively high during pulsed injection of water. This indicates that unsteady-state water injection, including intermittent injection and pulsed injection, might promote the instability of fluid flow rate, flow direction, and pressure distribution in the model. In this way, the water displacement efficiency was improved. However, the 
Table 9 Experimental schemes for optimizing water injection

\begin{tabular}{|c|c|c|c|c|}
\hline \multirow[t]{2}{*}{ Scheme } & \multirow{2}{*}{$\begin{array}{l}\text { Injection rate of bottom } \\
\text { water, } \mathrm{mL} / \mathrm{min}\end{array}$} & \multicolumn{3}{|c|}{ Subsequent water injection } \\
\hline & & $\begin{array}{l}\text { Injection } \\
\text { scheme }\end{array}$ & Injection rate & $\begin{array}{l}\text { Diagrams of } \\
\text { injection rate }\end{array}$ \\
\hline A & 4 & $\begin{array}{r}\text { Continuous } \\
\text { injection }\end{array}$ & $4 \mathrm{~mL} / \mathrm{min}$ & \\
\hline B & 4 & $\begin{array}{c}\text { Intermittent } \\
\text { injection }\end{array}$ & $8 \mathrm{~mL} / \mathrm{min}$ for $25 \mathrm{~min}$ and $0 \mathrm{~mL} / \mathrm{min}$ for another $25 \mathrm{~min}$ in one cycle & \\
\hline $\mathrm{C}$ & 4 & $\begin{array}{l}\text { Pulsed } \\
\text { injection }\end{array}$ & $\begin{array}{l}2 \mathrm{~mL} / \mathrm{min} \text { for } 15 \mathrm{~min}, 4 \mathrm{~mL} / \mathrm{min} \text { for } 15 \mathrm{~min}, 6 \mathrm{~mL} / \mathrm{min} \text { for } 15 \mathrm{~min} \text {, } \\
\text { and } 4 \mathrm{~mL} / \mathrm{min} \text { for } 15 \mathrm{~min} \text { in one cycle }\end{array}$ & \\
\hline
\end{tabular}

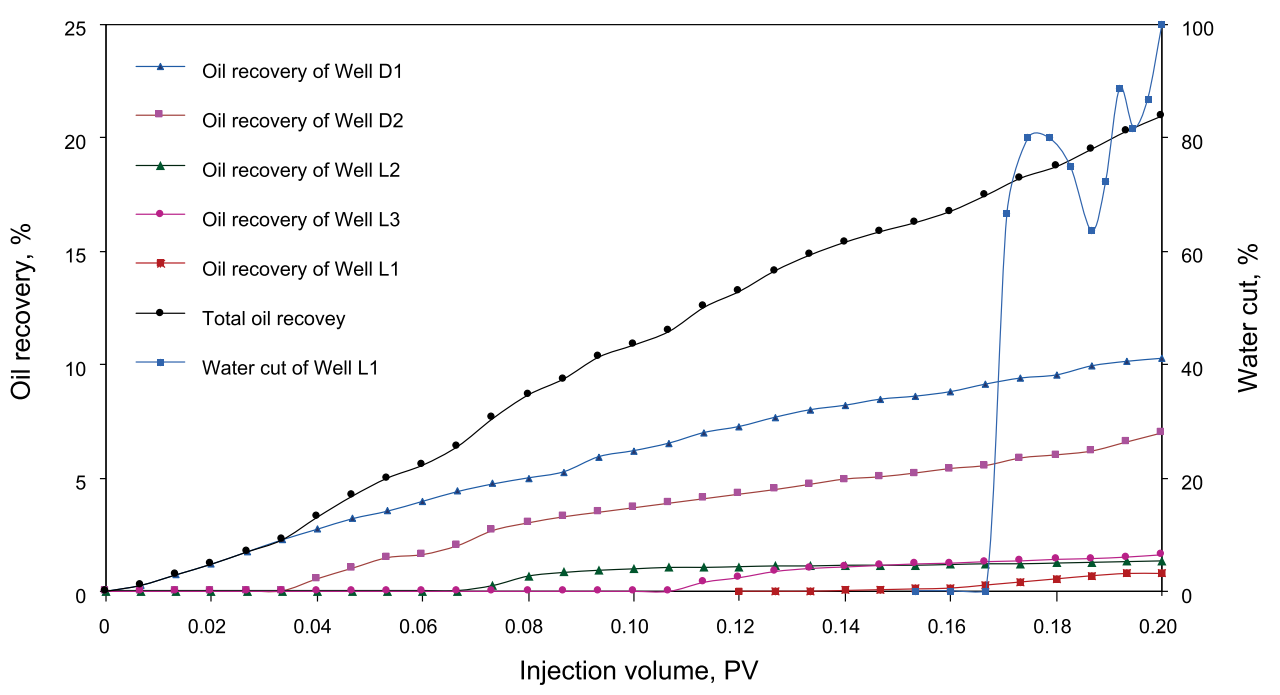

Fig. 8 Production performance of the bottom water drive at the depletion stage

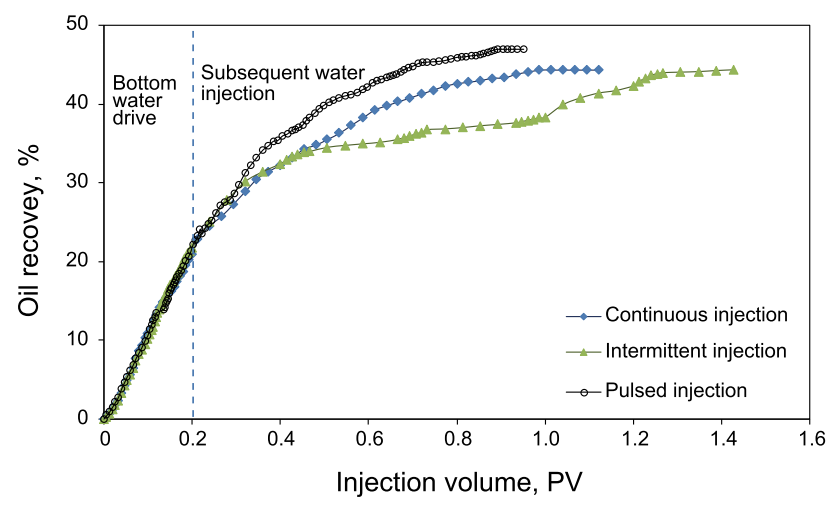

Fig. 9 Dynamic oil recovery curve

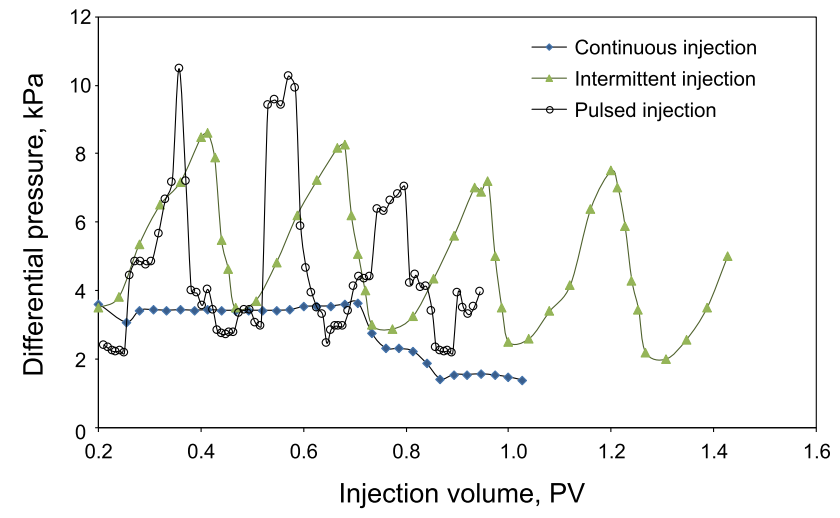

Fig. 10 Injection pressure during water injection 
displacement efficiency of intermittent injection was not as good as expected. This is due to the serious heterogeneity and the complex structure of fractures and caves in the fractured-vuggy reservoir model.

\subsubsection{Production performance at the subsequent water injection stage}

Figures 11, 12, 13, and 14 present the oil recovery and water cut of four production wells at the subsequent water injection stage, respectively.

Well L2 was the nearest to the injection well L1, and its well depth was similar to Well L1. Therefore, water breakthrough occurred immediately in Well L2 when the water was injected into Well L1. Correspondingly, the water cut of Well L2 increased to $100 \%$ rapidly. The incremental oil recovery was only about $0.1 \%-0.2 \%$.

Because Well D1 was drilled deeply into a cave that was near to injection well L1, water breakthrough occurred easily during subsequent water injection. The final oil recovery of Well D1 after intermittent injection was the highest among these three water injection modes. During intermittent injection, the injection pressure of Well D1 was high enough to suppress bottom water coning. Therefore, the oil/water co-production duration of Well D1 was long and its oil recovery was relative high. However, the incremental oil recovery was still at a low level, less
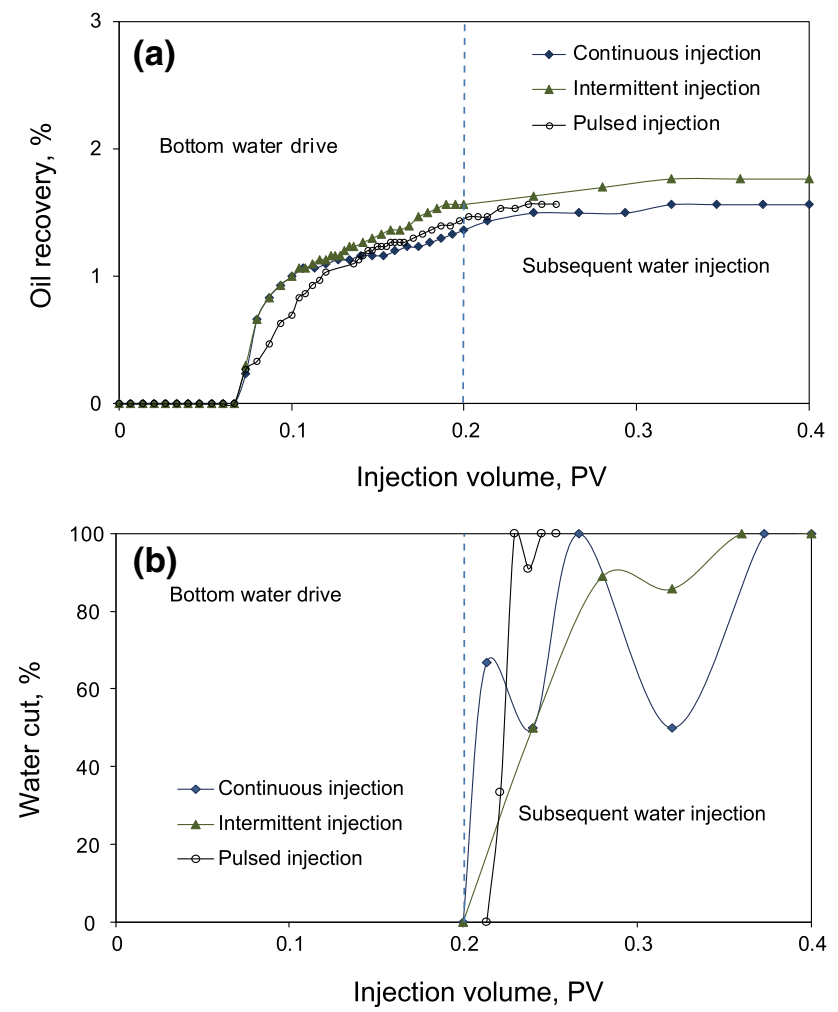

Fig. 11 Dynamic curves of oil recovery and water cut of Well L2
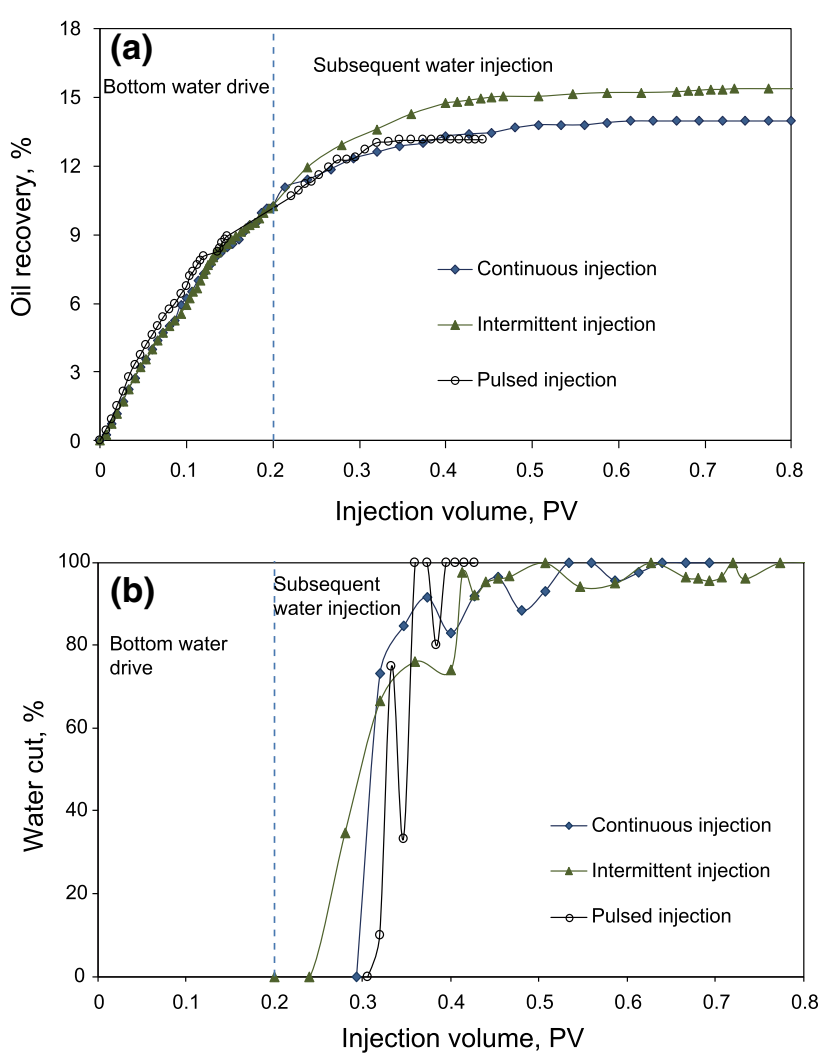

Fig. 12 Dynamic curves of oil recovery and water cut of Well D1

than $5.5 \%$. All these phenomena can be attributed to the well location, well depth, and the early water breakthrough.

Well D2 was comparatively far from Well L1 and the gravity effect in this well was relatively strong due to a bottom cave. The injection pressure was very low and only supplied bottom water energy during continuous water injection. So, the oil recovery of this well was not high after continuous water injection. On the other hand, the advantage of intermittent and pulsed injection of water was apparent. By changing the injection rate, pressure fluctuations were generated. The formation pressure distribution was changed and the oil-water flow was promoted between fractures and caves. In this way, the sweep efficiency and the displacement efficiency were improved.

Well L3 was also comparatively far away from injection well L1. Unlike Well D2, Well L3 was a fracture-well, and the well depth was the shallowest among those five wells. Therefore, the production performance of Well L3 was completely different from others. During intermittent injection, the injection pressure increased rapidly and water breakthrough occurred easily. However, after the water injection ended, water and oil were hard to redistribute due to the high viscosity resistance and slight gravity effect in fractures. This also led to a relative low oil recovery in Well L3 after immediate injection of water. During pulsed 

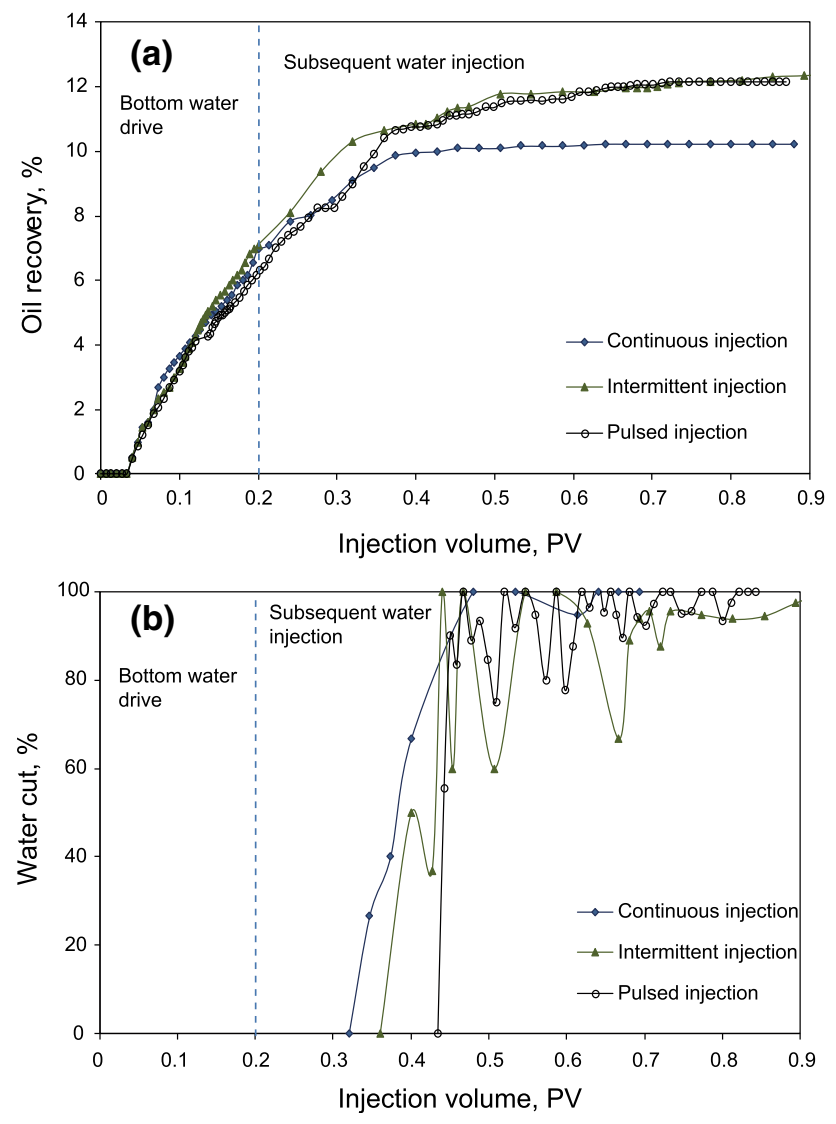

Fig. 13 Dynamic curves of oil recovery and water cut of Well D2

water injection, the high injection rate led to a high pressure increase and caused an early water breakthrough; however, the frequently fluctuated pressure induced a long duration of oil and water co-production, and led to a high final oil recovery.

Due to the complicated fractured-vuggy structure, well location, and well depth, not all the wells exhibited effective response to these three water injection modes. As a whole, the rate of increase of water cut during intermittent and pulsed injection of water was higher than that during continuous water injection. Unsteady-state injection of water indeed enhances water displacement efficiency to some extent compared with steady-state water injection.

\section{Conclusions}

(1) Based on a multi-well fractured-vuggy geological example unit in the Tahe Oilfield, a large-scale three-dimensional physical model was designed and constructed to simulate the fluid flow according to similarity criteria. Several factors were considered in
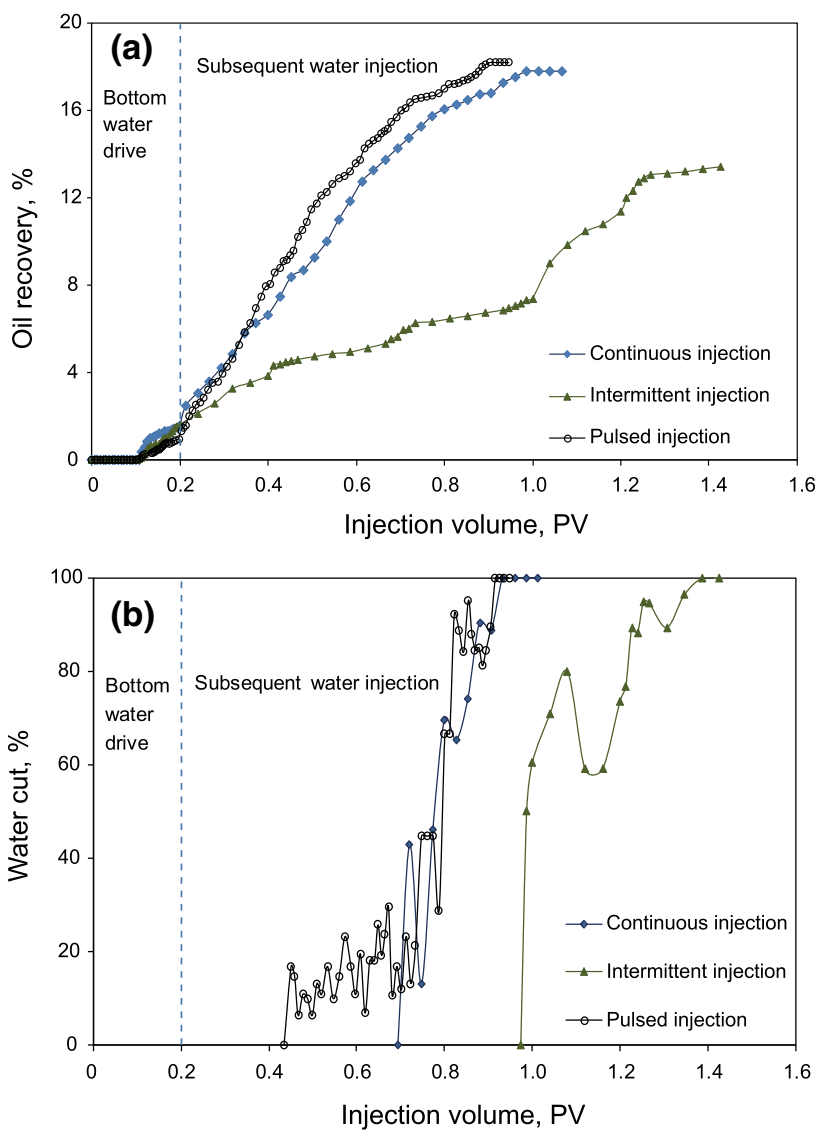

Fig. 14 Dynamic curves of oil recovery and water cut of Well L3

the design, including storage types, filling types, and filling percentages of storage space.

(2) The depletion production was conducted by changing the bottom water injection rate. Oil recovery of the physical model was similar to that of the field cases, which verified the reliability of the physical model.

(3) During pulsed injection of water, unbalanced formation pressure was caused, and the swept volume was expanded, and consequently the highest oil recovery increment was achieved. Intermittent injection presented the same effect as pulsed injection. However, similar to continuous injection, intermittent injection was influenced by factors including fractured-vuggy connected manner, well depth, and injection-production relationship. Continuous injection and intermittent injection finally get a comparatively low oil recovery.

(4) If a well is deep and close to the injection well, water breakthrough may occur earlier and water cut rises more rapidly. Besides, production performances of the fracture-well and the cave-well are completely different due to the difference in gravity effect and viscosity resistance. 
Acknowledgments This work was supported by China National Science and Technology Major Project (2011ZX05009-004, 2011ZX05014-003), National Key Basic Research and Development Program (973 Program), China (2011CB201006), and Science Foundation of China University of Petroleum, Beijing (2462014YJRC053).

Open Access This article is distributed under the terms of the Creative Commons Attribution 4.0 International License (http://creative commons.org/licenses/by/4.0/), which permits unrestricted use, distribution, and reproduction in any medium, provided you give appropriate credit to the original author(s) and the source, provide a link to the Creative Commons license, and indicate if changes were made.

\section{References}

Bünger F, Herwig H. An extended similarity theory applied to heated flows in complex geometries. Zeitschrift fur angewandte Mathematic und Physik. 2009;60(6):1095-111. doi:10.1007/s00033009-8076-8.

Cruz HJ, Islas JR, Perez RC, et al. Oil displacement by water in vuggy fractured porous media. In: SPE Latin American and Caribbean petroleum engineering conference, 25-28 March, Buenos Aires, Argentina; 2001. doi:10.2118/69637-MS.

Elkaddifi K, Shirif E, Ayub M, Henni A. Bottomwater reservoirs: simulation approach. J Can Pet Technol. 2008;47(2):38-43. doi: $10.2118 / 08-02-38$

Guo JC, Nie RS, Jia YL. Dual permeability flow behavior for modeling horizontal well production in fractured-vuggy carbonate reservoirs. J Hydrol. 2012;464-5:281-93. doi:10.1016/j. jhydrol.2012.07.021.

Haftkhani AR, Arabi M. Improve regression-based models for prediction of internal-bond strength of particleboard using Buckingham's pi-theorem. J For Res. 2013;24(4):735-40. doi:10.1007/s11676-013-0412-3.

Hou JR, Li HB, Jiang Y, et al. Macroscopic three-dimensional physical simulation of water flooding in multi-well fracturecavity unit. Pet Explor Dev. 2014;41(6):784-9. doi:10.1016/ S1876-3804(14)60093-8.

Hu XY, Li Y, Wang YQ, et al. Application of the probability method in a 3D geological model for petroleum geological reserves in fracturedcavity carbonate reservoirs: a case of Tahe-IV district, Tahe Oilfield. Pet Geol Recovery Effic. 2013;20(4):46-8 (in Chinese).

Jia YL, Fan XY, Nie RS, et al. Flow modeling of well test analysis for porous-vuggy carbonate reservoirs. Transp Porous Media. 2013;97(2):253-79. doi:10.1007/s11242-012-0121-y.

Kang YY, Tang DB. An approach to product solution generation and evaluation based on the similarity theory and ant colony optimisation. Int J Comput Integr Manuf. 2014;27(12):1090-104. doi:10.1080/0951192X.2013.855945.

Li HB, Hou JR, Li W, et al. Laboratory research on nitrogen foam injection in fracture-vuggy reservoirs for enhanced oil recovery. Pet Geol Recovery Effic. 2014a;21(4):93-6 (in Chinese).

Li JY, Chen XH. A rock-physical modeling method for carbonate reservoirs at seismic scale. Appl Geophys. 2013;10(1):1-13. doi:10.1007/s11770-013-0364-6.

Li M, Lou ZH, Zhu R, et al. Distribution and geochemical characteristics of fluids in Ordovician marine carbonate reservoirs of the Tahe Oilfield. J Earth Sci. 2014b;25(3):486-94. doi:10.1007/s12583-014-0453-3.

Li PL. The development of Ordovician fractured-cavity carbonate reservoirs in the Tahe Oilfield. Beijing: Petroleum Industry Press; 2013. p. 1-6 (in Chinese).

Lu ZY, Yang M, Dou ZL, et al. Study of geological model of pressure coning by water injection in well group TK440 of Ordovician reservoir in Tahe Oilfield, Tarim Basin, China. J Mineral Petrol. 2009;29(4):95-9 (in Chinese).

Lucia FJ, Kerans C, Jennings JW. Carbonate reservoir characterization. Soc Pet Eng. 2003;55(6):70-2. doi:10.2118/82071-MS.

Lv AM, Yao J, Wang W. Characteristics of oil-water relative permeability and influence mechanism in fractured-vuggy medium. Proc Eng. 2011;18:175-83. doi:10.1016/j.proeng.2011.11.028.

Nam JS, Park YJ, Kim JK, et al. Application of similarity theory to load capacity of gearboxes. J Mech Sci Technol. 2014;28(8):3033-40. doi:10.1007/s12206-014-0710-5.

Popov P, Qin G, Bi LF, et al. Multiphysics and multiscale methods for modeling fluid flow through naturally fractured vuggy carbonate reservoirs. SPE Eval Eng. 2009;12(2):218-31. doi:10.2118/ 105378-PA.

Presho M, Wo S, Ginting V. Calibrated dual porosity, dual permeability modeling of fractured reservoirs. J Petrol Sci Eng. 2011;77:326-37. doi:10.1016/j.petrol.2011.04.007.

Rong YS, Li XH, Liu XL, et al. Discussion about the pattern of water flooding development in multi-well fractured-vuggy units of carbonate fracture-cavity reservoirs in the Tahe Oilfield. Pet Geol Recovery Effic. 2013;20(2):58-61 (in Chinese).

Wang J, Liu HQ, Ning ZF, et al. Experiments on water flooding in fractured-vuggy cells in fractured-vuggy reservoirs. Pet Explor Dev. 2014;41(1):74-81 (in Chinese).

Wu YS, Di Y, Kang ZJ, et al. A multiple-continuum model for simulating single-phase and multiphase flow in naturally fractured vuggy reservoirs. J Pet Sci Eng. 2011;78:13-22. doi:10. 1016/j.petrol.2011.05.004.

Xiao MH, Cao Y, Zhang XB, et al. The research on the ancient Karst of Ordovician reservoir in Block 4 of Tahe Oilfield. Pet Geol Eng. 2010;24(3):31-3 (in Chinese).

$\mathrm{Xu}$ X, Tian SS, Xu T. The equivalent numerical simulation of fracturedvuggy carbonate reservoir. Mech Aerosp Eng. 2012;110-116: 3327-31. doi:10.4028/www.scientific.net/AMM.110-116.3327.

$\mathrm{Xu}$ X, Wei GQ, Yang ZM. The productivity calculation method of a carbonate reservoir. Pet Sci Technol. 2013;31(3):301-9. doi:10. 1080/10916466.2010.525586.

Yi B, Cui WB, Lu XB, et al. Analysis of dynamic connectivity of a carbonate reservoir with fractures and caves in the Tahe Field, Tarim Basin. Xinjiang Pet Geol. 2011;32(5):469-72 (in Chinese).

Yousef AN, Behzad T, Abolghasem KR, et al. A combined Parzenwevelet approach for detection of vuggy zones in fractured carbonate reservoirs using petrophysical logs. J Petrol Sci Eng. 2014;119:1-7. doi:10.1016/j.petrol.2014.04.016.

Zhang D, Li AF, Yao J, et al. A single-phase fluid flow pattern in a kind of fractured- vuggy media. Pet Sci Technol. 2011;29(10):1030-40. doi:10.1080/10916466.2011.553657.

Zhang K, Wang DR. Types of karst-fractured and porous reservoirs in China's carbonates and the nature of the Tahe Oilfield in the Tarim Basin. Acta Geol Sinica. 2004;78(3):866-72. doi:10.1111/ j.1755-6724.2004.tb00208.x.

Zhang P, Wen XH, Ge LZ, et al. Existence of flow barriers improve horizontal well production in bottom water reservoirs. In: SPE annual technical conference and exhibition, 21-24 September, Denver, Colorado, USA; 2008. doi:10.2118/115348-MS.

Zheng XM, Sun L, Wang L, et al. Physical simulation of water displacing oil mechanism for vuggy fractured carbonate rock reservoirs. J Southwest Pet Univ (Sci Technol Ed). 2010;32(2):89-92 (in Chinese).

Zhu R, Lou ZH, Jin AM, et al. Fluid distribution and dynamic responses to exploitation in fracture-cave unit S48 in Tahe Oilfield. J Zhejiang Univ (Eng Sci). 2009;43(7):1344-8 (in Chinese).

Zuta J, Fjelde I. Mechanistic modeling of $\mathrm{CO}_{2}$-foam processes in fractured chalk rock: effect of foam strength and gravity forces on oil recovery. In: SPE enhanced oil recovery conference, 19-21 July, Kuala Lumpur, Malaysia; 2011. doi:10.2118/144807-MS. 